\title{
The Effect of Internship on Employability ---Take the Example of College Students Majoring in Management
}

\author{
Tian Guomei ${ }^{1, a^{*}}$ \\ ${ }^{1} 24$ Wangjiang Road, Sichuan University, Chengdu, China \\ atiangmfree@163.com
}

\section{Keywords: College Students; Internship; Employability; STW Education}

Abstract. Employability refers to the ability to obtain t, maintain and to obtain a new employment. We study the effect of internship on college students through in-depth interviews, the grounded theory and the content analysis, and reach the conclusions:1) the lagging of STW education is the most significant background characteristics in China, 2) the effect of internship on employability is to make up for the lack of STW education in early stages, to help them understand the differences between school and work, but not to improve the abilities and skills.

\section{Introduction}

According to a survey in 2010 the unemployment rate of college graduates was $28.1 \%$ and more than 190 million graduates were in unemployment, which has become a common concern to improve their employability. It has been proved that internship was the main way for students to improve their employability in western countries. But in China, owing to the lack of institutional framework to participate in the social practice of teenagers, enterprises and schools were in confusion, not knowing how and what to do. Except for tourism management, education, nursing and some other professions that schools offered them the opportunity of practice and the supervision during the practice, for most majors, there was only certain requirements for them, the students have to look for the internship and managed it by themselves. Researches on practice did not pay much attention to the relationship between the main subjects in practice, and study on the effect of the internship was limited to skills and abilities, other aspects do not receive enough attention such as work attitude, work values, etc. Based on the unique situation in China, the difficulties for college students to find a job, we study the relationship between the main subjects, the effect of the internship from the perspective of employability, which is of great significance to promote the employment of college graduates.

\section{Literature Review}

\section{Employability}

Beveridge first proposed the term "Employable" in 1909, which aroused wide attention of scholars from home and abroad. Robinson (2000) defined the employability as the capacity to obtain, maintain and do a certain job from the perspective of capacity; Knight (2001) considered apart from abilities, employability included professional achievements, understanding and personal characters which were beneficial to the ability of obtaining a job and making successful career selections; Grip de Andries et al. took the economic environment and the conditions of the labor market as a part of the concept; Due to the complexity and multidimensional nature of employability, its definition was not easy, and still in exploration, but currently both scholars and practitioners have reached an agreement that it should include following aspects,1) from the aspect of skills and competencies, it included knowledge, skills, ability and other invisible factors, such as attitude, beliefs, values, interests, hobbies and motivations;2) personal factors, such as self-cognition, coping ability, personal characteristics and self-promotion, etc.;3) the background of employment, such as the level of support in work, the difficulty of getting well with colleagues, etc.;4) environmental factors, such as the state of the employer, the incentive to work and labor market requirements, etc.. 


\section{The effect of internship}

With a well-developed intern system, researches on the internship in foreign countries started very early and received rich results. Study on the effect of practice was from two perspectives. From the view of organizational socialization, it was a small organizational socialization process, the interns experienced similar conflicts between job requirements and his expectations during the internship, and it could help them to reduce work shock and promote the transfer from school to work [3].

From the view of career development, internship was an important part of career exploration and a necessary condition for career development and career success. Existing theories believed that the career success and job satisfaction was based on finding a job which was in match with his personality traits and expectations[5]. To get the match, it was important to understand his characteristics and different jobs. Because the internship gave them a view of the knowledge, skills, abilities, interests and values in need, firstly the internship helped them to understand the enterprises' needs and to assess and develop their employability and to help them to develop greater crystallization of vocational self-conceptp[3];secondly, to develop his abilities such as communication ability, adaptability, team work ability[4]; thirdly, because of the contact with the enterprises , the graduates could get more informal recruitment information and better employment opportunities.

However, owing to the influence of traditional education modes, shools do not pay much attention to the internship, its management was not standardized, and the employment guidance center did not fully played its role of promoting employment.The students' career preparation was insufficient, and the enthusiasm of domestic enterprises to participate in the practice was low, reseaches on the effects of internship in western countries did not apply to domestic conditions

There were some reseaches on the effects of internship based on Chinese situation. Some scholars studied the effect of the internship and its influencing factors from the perspective of Organizational Socialization, such as the Huanghe (2009), but he only gave a literature review on existing theories, without taking the Chinese background into account; some scholars took the internship as a whole and studied its effect on employability, ,employment tendency, however, the factors affecting the effect of the internship and the reason why internship was beneficial were not involved; some scholars studied the phonamena or bahaviors during the internship such as communication skills], bad adaptation[16], but this kind of research was mainly focused on the effect of the internship, the factors influencing the effect of practice were only discussed theoretically and lack of empirical testing.

Through the literature review, we can find that study on internship in China was far from enough. For the lack of attention on the special background in China, the relationship between the main subjects of the practice is not clear,and the research on the effect of the internship was limited to the employment abilities, and it was important to study the relationship between the different subjects and the effect of internship on employability in China.

\section{Research design and methodology}

At present, the domestic scholars have not realised the special background in China. Reseaches on the motivation of college students, the role of government and enterprises in practice, the relationship between interns and employees were far from enough, so large scale quantitative researches were not suitable for the study of the effect of the internship.

Moreover the internship was complex and its effect was difficult to by measured by some items in the questionaire. The students were unable to fully recognize some changes during the internship, and needed to be guided by professionals. So in this paper we used qualitative research methods. We tracked 20 internships of 11 respondents through in-depth interviews and diaries. From preliminary data analysis, we found that preparations before the internship was one factor affecting its effect, so the increased the second round of interview, and invited the respondents to review the career development education they recieved, the process of their self-exploration and exploration to work.

Based on the Grounded Method(Strauss \& Corbin ,1990), we used open coding and theme coding to code the 11 text , and to ensure the accuracy of coding we invited 2 Management Master's students 
and 1 doctoral students to code independently, and then compared the differences among the coding and discussed in groups (including 1 management professors, doctoral tutor, 2 doctoral and 4 graduate students), continued to adjust and improve until the theoretical saturation.

\section{Analysis}

\section{Sample}

Interns are main participants and direct beneficiaries of the internship, could truly feel the changes and benefits of the internship, the attitude of shools, enterprises etc., the problems existing during the process. Based the feelings of the interns, we studied its effect on employability.

The data collection was from November 2013 to May 2014. The sample included 6 males, 5 females; 7 undergraduates and 4 postgraduate; 4 people with only 1 internship, 5 people with 2 internship, 2 people with 3 internship; 3 respondents first practice in grade 2, 4 in grade 3,4 in grade 4, the time of the interview was 10 hours, then was transcribed and got more than 135,000 words.

\section{Analysis}

1) The serious lagging of STW education for college students

STW (School to Work) education is a general term for all the education aiming at helping young people to transfer from school to work, including career guidance, vocational education, etc..At present, the schools have not realised the need to help young people to transfer from school to work world. The main tasks of schools is knowledge teaching without vocational education in any forms $(\mathrm{B} / 35 / 4-6 ; \mathrm{D} / 5 / 28-33 ; \mathrm{J} / 18 / 21)$; in the universities the areer education for college students is a mere formality(B/31/42-B/32/11), without relevant curriculums ,just as the interviewee said the career development was only 0.5 score with only 1 lesson(D/6/17-20), the role of the employment guidance center is limited to publish recruitment information, and of little importance to the career development and career choice of college students(B/34/11-28; D/7/1-2). From the view of schools, they have not realized importance of STW education.

Nowadays, enterprises have not realised their responsibilities and obligations in the STW education. Their motivation to recruit interns was to reduce the cost of human resources(E/3/40-42), remedy the short-term shortage(E/3/38; J/11/44-J/12/4), without considering the career development.

As for students, they did not have enough exploration to themselves and the work world at middle and high schools. All of the 11 respondents did not have any exploration of themselves and the world of work before the university.Because of the lack of understanding of differnet professionals they were blind when chooseing their professional at the entrance examination (F/4/8;G/9/20-22;J/18/31-32).

They had no clear career development planning, lacked the awareness of themselves and the work world(B/32/14-16; $\mathrm{C} / 5 / 27-29)$, put too much emphasis on the brand of the company when choosing the internship, without considering their benefits of the internship(B/5/13-14; C/4/4-5; I/8/10-14), have too much expectations(A/4/11; D/1/26; H/2/27; I/1/24-25). Their motivation of internship was to cognitive the society, understand the target position, and to accumulate work experience, which is in contrast with the reality of work. The interns lacked of initiative during the internship, and were always passively accepted the task, ( A/3/3-5; E/6/4) .

In summary, schools have not realized the importance of STW education; the enterprises have not recognized their responsibilities and obligations; students lacked understanding of the professions, had too much expectation, lack of initiative during the internship. STW education in China was seriously lagging. Schools, enterprises and individuals were not well prepared for the internship.

\section{2) Current status of internship}

The conflicts between internship and learning tasks in college. Due to the absence of STW education in middle and high schools, college students had to make up for it when they found its necessarities in practice, which was in conflict with the university's educational mission inevitably. Respondents mentioned that they missed the course for a half year because of a internship arranged by the school $(\mathrm{B} / 1 / 5-9 ; \mathrm{F} / 1 / 9 ; \mathrm{I} / 1 / 26)$. Respondent $\mathrm{C}$ mentioned she had to go back and forth between 
Changchun and Beijing in order to continue the internship in Beijing (C/3/32-35). Respondents also mentioned that the practice did harm to formal employment, as B said that she missed some opportunities of good jobs during the Autumn Recruitment because of a internship (B/4/38-43).

The conflicts between interns and enterprises. Students thought too much of the brand of the company when choosing the internship unit, without considering whether he was in match with the conpany or the bebefits of the internship, leading to the unmatching. Moreover the internships were not for employment, which limited the input given to them. The conflicts were in several aspects, firstly, the confusion in the management of interns, the interns did not have a fixed boss, the tasks for them were not clear (A/2/18; F/1/29-31; G/8/10-14). Just as E said "'There was a supplementary term in the agreement that I had to do the things that they asked me to do.It was usual that the official staff would ask me for help when they found that I was free"(E/5/26-31).Secondly, the tasks were simple with little autonomy, such as B and $\mathrm{J}$ mentioned that their tasks were highly fixed, daily cleaning, toilet brushing, folding the quilt etc. ( B/1/43; F/2/1-3;J/2/6).

For enterprises, the government had no preferential policies to those who provided internship positions; the interns were of little benefit to the company. Owing to lack of understanding of interns, it was reasonable and understandable that the tasks given to them were single with little autonomy.

3) The effect of internship on employability

From the view of individual characteristics, the effect of the internship on employability was mainly reflected on self-cognition. The internship can help students to enhance their self-awareness, and find the lack of their career preparation, as the respondents said the internship helped them to find that English was one of the factors that restricted their development(B/12/4-5), their perspective was too narrow and their overall thinking was far from enough(J/5/1-2). It could help them to have a better understanding of the gap between expectations and reality. There were often differences between the reality and their expectations that the work could be tiring, hard, boring and with great pressure, but it was the presence of negative content that make the work real(C/7/19-23;H/8/5-11; K/1/5-8).

From the view of employment background, the internship helped them have a better understanding of work. The difference in interpersonal relationship and the way of finishing a job between school and work, which make them better prepared for future career choices.

From the cognitive of work world. The internship helped students understand the target position (F/5/9-12;H/6/18-23;I/4/41), the differences between the different enterprises (A/5/35-38;F/2/36-39; $\mathrm{G} / 5 / 5-9)$. The differences between school and work in interpersonal perspective was mainly reflected on the competition between colleagues, the difference in sharing resources between different departments, and the hierarchy between the leaders and his colleagues in the workplace(E/1/33-35; $\mathrm{A} / 7 / 21-24 ; \mathrm{H} / 1 / 39-42 ;$ ). Changes in the way of work were that the appraisal was result-oriented at school, while at work, besides results, work attitude, work processes were also important parts of the appraisal(D/4/39-44; E/1/39-42; K/2/38-41); and the way of handling errors was different, it was often mutual prevarication and new employees took the blame, unlike at schools that we shared(K/2/1-5).

From the view of skills and competency. Existing researches have shown that the competency of a job included knowledge, skills, abilities and work attitudes, work values, and so on. The effect of internship on skills and abilities of internship is the focus of the existing literature, but in this paper we found that the improvement for college students in communication, organization and coordination capacity and other capacity was not significant owing to the unsufficent preparations of the students for the internship, lack of attention to the interns of the company, single internship tasks with poor autonomy. The improvement of skills were mainly reflected on better operation of office software (C/1/32-37;E/1/30-32;F/5/42-44), and the improvement of abilities was reflected on compressive capacity (B/8/37-44; $\mathrm{F} / 5 / 31 ; \mathrm{H} / 8 / 9-10)$ and the ablity to adapt to environment(G/3/36-38; H/1/32-35).

The greatest influence of internship on the competence was to cultivate good working attitudes. It showed that the internship helped the students to be more paractical instead of impetuous(H/1/32-35), improve their initiative (D/4/32-38;H/1/35-39;I/11/16-26), sense of responsibility(B/13/30-33; G/3/ 34-36), and strengthen their confidence in career development(I/4/20-24;J/13/20-24; K/7/23-29). 


\section{Conclusions and suggestions}

\section{Conclusions}

The lagging of STW education is the most significant background of the internship in China.and one of the key factors that restrict the effect of the internship.

The conflicts between the internship and college education tasks, between interns and the enterprises. The students had to make up for the lack of STW education by themselves when they found its necessity, which was in conflict with the college's educational tasks. Their expectations of internship were too high, which was in conflict with the reality that enterprises did not give them much attention, the management was in confusion, and the tasks given them were single with poor autonomy.

The effect of the internship on college students' employability was not to improve their skills and abilities, but to remedy the lack of STW education in middle and high schools, to help them understand the differences between the school and the world of work, to cultivate good working attitudes, and to beter prepared for future career choices.

\section{Suggestions}

The government should build a nationwide internship planning, and offer enterprises and schools the way of taking part in the internship; secondly, provide preferential policies for the enterprises that offer positions for the interns to improve their enthusiasm to participate in the internship.

For enterprise, they should change their attitudes to interns, enhance understanding of their role of improving their employability, provide opportunities for interns, strengthen the practice management.

For schools, from the beginning of high schools or even earlier they should carry out vocational education, and guide them to explore themselves and the work world, help them make career planning; cooperate with enterprises to create more internship opportunities for students; strengthen the supervision and guidance during the internship; make full use of the employment guidance center.

For individuals, they should enhance their awareness of career planning, improve their ability of career planning; in the choice of enterprise not only consider its band, but also the match between themselves and enterprises and the benefits; reduce their expectations and to extend the practice time.

\section{Limitations and future researches}

Limitations.First, we only interviewed students, without interviewing teachers and enterprises that had an effect on the internship, resulting in that the research was influenced by the college students' subjective cognition; secondly, we mainly interviewed the interns after the internship and asked them to recall it, the contents may be influenced by the missing of details, or the deviation of memory.

Future reseach. firstly, increase samples of students in the internship, and invite them to record the problems and solutions and benefits during the process, in order to obtain the more real, complete information; secondly, as the ultimate goal of the internship is to provide their employability and help them to get a successful career, we can track the 11 respondents in the future and study its effect on the employability, career development and career success.

\section{References}

[1]Hall. D. T.. Careers in organizations. Santa Monica. CA: Goodyear,1976.

[2]Mason,G.,Williams, G. and Cranmer,S.,Employability Skills Initiatives in Higher Education, 2009.

[3]Feldman,D.c. Work Careers:A Development Perspective,Jossey-Bass,San Francisco,CA,2002,.

[4]Neill,N.et al.,The Influence of Part- time Work on Student Placement. Journal of Further and Higher Education. 2004(28),pp.123-137.

[5]Lei Jie,The research on the assessment and the inluencing factors of nusing students that is 
unadaptable during the internship [D],Suzhou university,2013. 